\title{
Thermal expansion of doped lanthanum gallates
}

\author{
K T JACOB*, S JAIN, V S SAJI and P V K SRIKANTH \\ Department of Materials Engineering, Indian Institute of Science, Bangalore 560 012, India
}

MS received 15 January 2010

\begin{abstract}
Thermal expansion of several compositions of $\mathrm{Sr}$ and $\mathrm{Mg}$-doped $\mathrm{LaGaO}_{3}$ including an $A$-site deficient composition $\left(\mathrm{La}_{0.9} \mathrm{Sr}_{0.1}\right)_{0.98}\left(\mathrm{Ga}_{0.8} \mathrm{Mg}_{0.2}\right) \mathrm{O}_{2.821}$ were measured in the temperature range from 298 to $1273 \mathrm{~K}$. The effect of doping on thermal expansion was studied by varying the composition at one site of the perovskite structure (either $A$ or $B$ ), while keeping the composition at the other site invariant. Thermal expansion varied nonlinearly with temperature and exhibited an inflexion between 550 and $620 \mathrm{~K}$, probably related to the change in crystal structure from orthorhombic to rhombohedral. The dependence of average thermal expansion coefficient $\left(\alpha_{\text {av }}\right)$ on the dopant concentration on either $A$ or $B$ site of the perovskite structure was found to be linear, when the composition at the other site was kept constant. Mg doping on the $B$-site had a greater effect on the average thermal expansion coefficient than $\mathrm{Sr}$ doping on the $\boldsymbol{A}$-site. Cation deficiency at the $A$-site decreases thermal expansion when compositions at both sites are held constant.
\end{abstract}

Keywords. Coefficient of thermal expansion; perovskite; doped lanthanum gallate; solid oxide fuel cells.

\section{Introduction}

Perovskite compositions of the $\mathrm{ABO}_{3}$ type with various $A$ and $B$ site substitutions have been able to meet many of the material requirements imposed on components of solid oxide fuel cell (SOFC) stack. SOFCs operate at elevated temperatures ranging from 1073 to $1273 \mathrm{~K}$ and the components of the cell are subjected to temperature differentials during fabrication, start-up and operation. Since the components are in intimate mechanical contact, any stress generated due to their thermal expansion mismatch during thermal cycling could lead to catastrophic failure of the cell. The functional materials must have similar thermal expansions to avoid mechanical stresses. Hence it is useful to study the thermal expansion of SOFC materials and tailor them to ensure the absence of significant stress build-up.

Yttria-stabilized zirconia is the electrolyte currently used in SOFC and its thermal expansion behaviour is well established. There has been a surge of interest in novel solid electrolyte materials for SOFC application at lower temperatures. The foremost among them is $\mathrm{LaGaO}_{3}$-based oxides with perovskite structure, which show far superior ionic conductivity compared to yttria-stabilized zirconia (Ishihara et al 1995). Sr- and $\mathrm{Mg}$-doped $\mathrm{LaGaO}_{3}$ oxides have the highest electrical conductivity among them, with ionic transference number close to one over a wide range of oxygen pressures, and are used as interconnect and electrolyte materials in SOFC (Hayashi et al 1999). Data

*Author for correspondence (katob@materials.iisc.ernet.in) on the thermal expansion of doped $\mathrm{LaGaO}_{3}$ has been reported by Feng and Goodenough (1994), Stevenson et al (1997), Ishihara et al (1998), Hayashi et al (1999, 2000) and Aleksandrovskii et al (2001).

Stevenson et al (1997) measured linear thermal expansion (TEC) coefficient of two Sr- and $\mathrm{Mg}$-doped $\mathrm{LaGO}_{3}$ samples from 293 to $1473 \mathrm{~K}$. The TEC was found to increase with increasing temperature. The average thermal expansion coefficients of the doped samples were higher than that of YSZ and increased with doping on both $A$ and $B$-sites (Stevenson et al 1997). Ishihara et al (1998) measured the thermal expansions of $\mathrm{La}_{1-x} \mathrm{Sr}_{x} \mathrm{Ga}_{0.8} \mathrm{Mg}_{0.2} \mathrm{O}_{2 \cdot 9-x / 2}$ at $x=0.1$ and $x=0.2$ and reported that the average thermal expansion coefficient of $\mathrm{La}_{0.9} \mathrm{Sr}_{0.1} \mathrm{Ga}_{0.8} \mathrm{Mg}_{0.2} \mathrm{O}_{2.85}$ between 298 and $1273 \mathrm{~K}$ was similar to that of YSZ. Although their data show gradual increase in the slopes of thermal expansion with temperature, the authors conclude that the temperature dependence of expansion is insignificant and the phase transition found in $\mathrm{LaGaO}_{3}$ around $420 \mathrm{~K}$ disappeared in the thermal expansion curve of doped$\mathrm{LaGaO}_{3}$ (Ishihara et al 1998). Hayashi et al (2000) measured TEC of $\mathrm{La}_{0.9} \mathrm{Sr}_{0.1} \mathrm{Ga}_{1-y} \mathrm{Mg}_{y} \mathrm{O}_{3-\delta}(y=0 \cdot 1$ to $0 \cdot 3)$ and $\mathrm{La}_{0.8} \mathrm{Sr}_{0.2} \mathrm{Ga}_{1-y} \mathrm{Mg}_{y} \mathrm{O}_{2.85}(y=0 \cdot 1,0 \cdot 2)$ in the temperature range from 100 to $873 \mathrm{~K}$ and showed that doping increases thermal expansion. Pure $\mathrm{LaGaO}_{3}$ exhibited a shrinkage related to orthorhombic to rhombohedral structure transition at $421 \mathrm{~K}$ (Hayashi et al 2000). The dimensional change became smaller and broader with doping. The transition temperature increased with $\mathrm{Mg}$ content and decreased with $\mathrm{Sr}$ concentration (Hayashi et al 2000). They examined TEC of $\mathrm{La}_{1-x} \mathrm{Sr}_{x} \mathrm{Ga}_{1-y} \mathrm{Mg}_{y} \mathrm{O}_{3-\delta}$ at $200 \mathrm{~K}$ as a function of oxygen vacancy and concluded that TEC 
increases linearly with oxygen vacancy concentration regardless of the relative distribution of dopants on the two sites (Hayashi et al 2000). This suggests that Sr on La-site and $\mathrm{Mg}$ on Ga-site have equal effect on thermal expansion. Aleksandrovskii et al (2001) have shown that the unit cell volume of $\mathrm{LaGaO}_{3}$ increases almost linearly with $\mathrm{Sr}+\mathrm{Mg}$ content.

To remove the discrepancies in the literature on thermal expansion, new measurements were conducted on the system $\mathrm{La}_{1-x} \mathrm{Sr}_{x} \mathrm{Ga}_{1-y} \mathrm{Mg}_{y} \mathrm{O}_{3-0.5(x+y)}(0 \cdot 1 \leq x \leq 0 \cdot 2 ; 0 \cdot 1 \leq y$ $\leq 0 \cdot 2$ ) in the temperature range from 298 to $1273 \mathrm{~K}$ using a horizontal quartz dilatometer. The effect of cation deficiency on the $A$-site on thermal expansion of doped $\mathrm{LaGaO}_{3}$ was explored as this has not been fully elucidated in the literature. The results have been interpreted in relation to ionic radii and oxidation state of the cations, oxygen nonstoichiometry and crystal structure.

\section{Experimental}

\subsection{Sample preparation and characterization}

Polycrystalline samples of superionic conductor, $\mathrm{La}_{1-x} \mathrm{Sr}_{x}$ $\mathrm{Ga}_{1-y} \mathrm{Mg}_{y} \mathrm{O}_{3-\delta}(\delta=0 \cdot 5(x+y))$ (LSGM), were prepared by conventional ceramic processing. Samples were prepared using powders of $\mathrm{La}_{2} \mathrm{O}_{3}, \mathrm{SrCO}_{3}, \mathrm{MgO}$ and $\mathrm{Ga}_{2} \mathrm{O}_{3}$ of purity $>99.9 \%$. Before weighing, $\mathrm{La}_{2} \mathrm{O}_{3}$ and $\mathrm{MgO}$ were calcined at $1273 \mathrm{~K}$ in dry argon for $12 \mathrm{ks}$ to remove moisture. The powders were mixed and ground in an agate ball mill and precalcined at $1473 \mathrm{~K}$ in air for $120 \mathrm{ks}$. The calcined powders were ground in an agate ball mill, sieved $(160 \mu \mathrm{m}$ mesh $)$ and cold isostatically compacted at $500 \mathrm{MPa}$. The samples were sintered at $1723 \mathrm{~K}$ in air for $30 \mathrm{ks}$ with intermediate regrinding, sieving and compacting. The final sintering was done at $1773 \mathrm{~K}$ for $240 \mathrm{ks}$. The prolonged heat treatment was necessary to dissolve metastable phases that form during synthesis and obtain equilibrium phase composition. The presence of impurity phases influences thermal expansion. There is no change in thermal expansion for sintering time $>180 \mathrm{ks}$. To prevent $\mathrm{Ga}$ depletion from the surface and grain boundaries by volatilization, the compacted samples were buried in loose powder of the same composition. The dimensions of the sintered bars were $\sim 3.5 \times 3.5 \times 55 \mathrm{~mm}$. The faces of the sintered compact were cut and polished. Each composition was examined by X-ray diffraction and all the samples were confirmed to be essentially single phase with perovskite structure. Traces of secondary phase, $\mathrm{LaSrGa}_{3} \mathrm{O}_{7}$ were observed in $\left(\mathrm{La}_{0.8} \mathrm{Sr}_{0.2}\right)\left(\mathrm{Ga}_{0.9} \mathrm{Mg}_{0.1}\right) \mathrm{O}_{2.85}$. The intensity of impurity reflection in XRD pattern was $<3 \%$ of the strongest perovskite peak. The overall composition was verified by inductively-coupled plasma (ICP) spectroscopic analysis.

The bulk density of the sintered bars was determined by Archimedes' liquid displacement technique using dis- tilled water as the medium. The densities of the samples were 92 to $94 \%$ of the theoretical values.

\subsection{Measurement of thermal expansion}

Linear thermal expansion measurements were conducted on sintered rods $(3 \times 3 \times 50 \mathrm{~mm})$ during heating at $0.067 \mathrm{~K} / \mathrm{s}$ from $298 \mathrm{~K}$ to $1273 \mathrm{~K}$ in air using a horizontal quartz dilatometer which was calibrated with a sapphire single crystal.

\section{Results and discussion}

The thermal expansion curves for the series $\left(\mathrm{La}_{0.8} \mathrm{Sr}_{0.2}\right)$ $\left(\mathrm{Ga}_{1-y} \mathrm{Mg}_{y}\right) \mathrm{O}_{2.9-0.5 y}$ for $y=0 \cdot 1,0 \cdot 15$, and 0.2 are shown in figure 1. It is evident from the figure that the change in length and therefore, the linear thermal expansion coefficient is a nonlinear function of temperature. There are inflexions in the thermal expansion curves in the temperature range from 570 to $610 \mathrm{~K}$. The thermal expansion of $\mathrm{LaGaO}_{3}$ increases slightly with magnesium concentration on the Ga-site when $A$-site composition is kept invariant. $\mathrm{LaGaO}_{3}$ has an orthorhombic structure at room temperature and transforms to rhombohedral symmetry around $420 \mathrm{~K}$ (Marti et al 1994). It has been reported that the substitution of magnesium for gallium on the $B$-site increases the transition temperature (Hayashi et al 2000). This phase transition manifests itself as an inflexion or

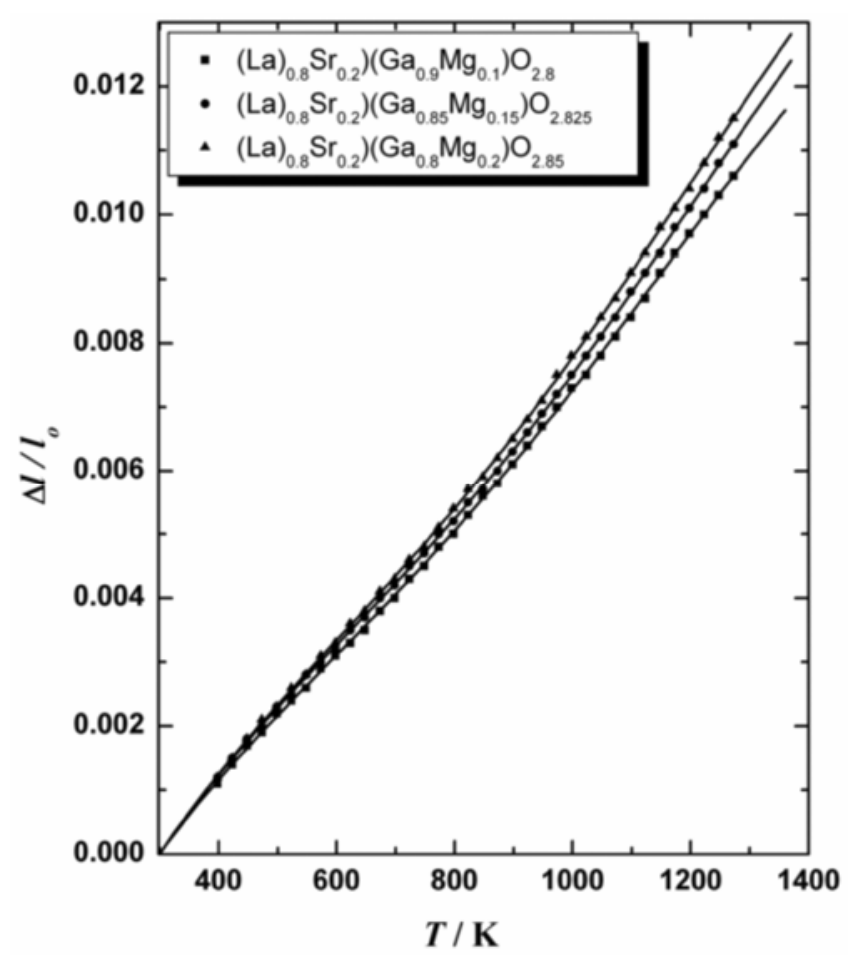

Figure 1. Thermal expansion of $\left(\mathrm{La}_{0.8} \mathrm{Sr}_{0.2}\right)\left(\mathrm{Ga}_{1-y} \mathrm{Mg}_{y}\right) \mathrm{O}_{2 \cdot 9-0.5 y}$ for $y=0 \cdot 1,0.15$ and 0.2 from 298 to $1273 \mathrm{~K}$. 
Table 1. Coefficients of the polynomial expression for thermal expansion as a function of temperature

\begin{tabular}{lccccr}
\hline & \multicolumn{5}{c}{ Coefficients } \\
\cline { 2 - 6 } Sample & $B_{0} \times 10^{3}$ & $B_{1} \times 10^{5}$ & $B_{2} \times 10^{8}$ & $B_{3} \times 10^{11}$ & $B_{4} \times 10^{15}$ \\
\hline$\left(\mathrm{La}_{0.8} \mathrm{Sr}_{0.2}\right)\left(\mathrm{Ga}_{0.9} \mathrm{Mg}_{0.1}\right) \mathrm{O}_{2.85}$ & -5.32 & 2.5282 & -3.2454 & 2.7609 & -7.8529 \\
$\left(\mathrm{La}_{0.8} \mathrm{Sr}_{0.2}\right)\left(\mathrm{Ga}_{0.85} \mathrm{Mg}_{0.15}\right) \mathrm{O}_{2.825}$ & -5.94 & 2.8587 & -3.7475 & 3.0704 & -8.3566 \\
$\left(\mathrm{La}_{0.8} \mathrm{Sr}_{0.2}\right)\left(\mathrm{Ga}_{0.8} \mathrm{Mg}_{0.2}\right) \mathrm{O}_{2.8}$ & -5.98 & 2.8628 & -3.7434 & 3.1166 & -8.6035 \\
$\left(\mathrm{La}_{0.9} \mathrm{Sr}_{0.1}\right)\left(\mathrm{Ga}_{0.8} \mathrm{Mg}_{0.2}\right) \mathrm{O}_{2.85}$ & -3.34 & 1.1314 & -0.0495 & -0.14894 & 1.5281 \\
$\left(\mathrm{La}_{0.9} \mathrm{Sr}_{0.1}\right)_{0.98}\left(\mathrm{Ga}_{0.8} \mathrm{Mg}_{0.2}\right) \mathrm{O}_{2.821}$ & -5.69 & 2.8681 & -4.1972 & 3.6087 & -10.1985 \\
\hline
\end{tabular}

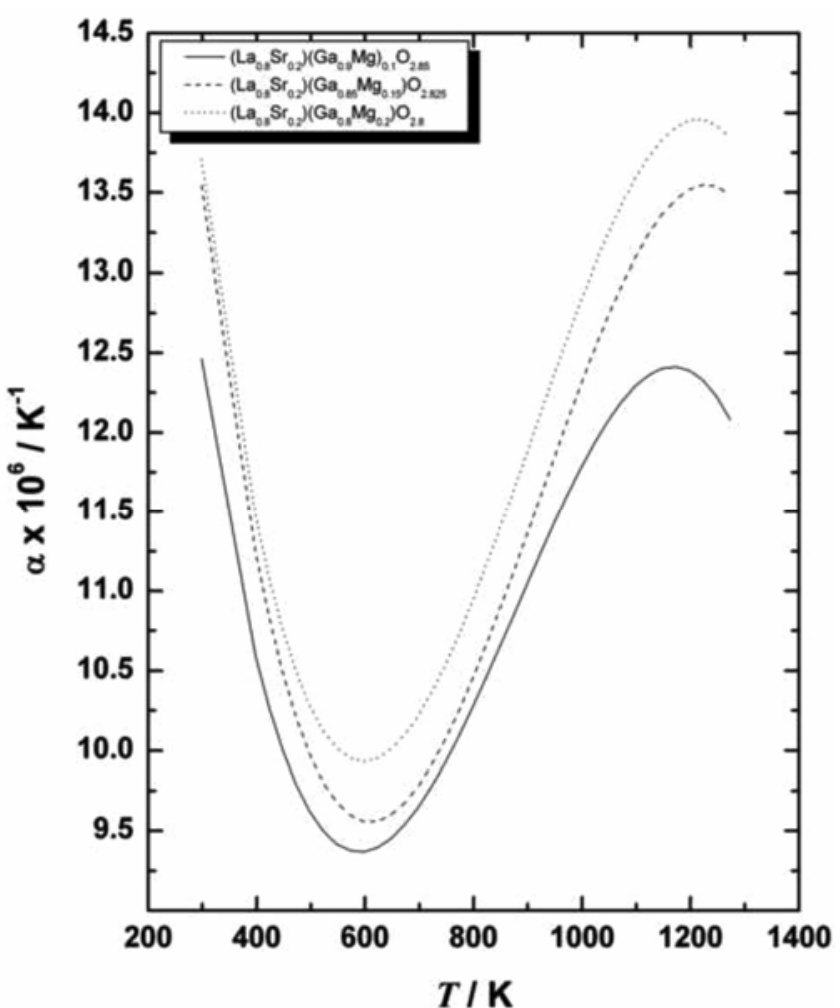

Figure 2. Variation of thermal expansion coefficient of $\left(\mathrm{La}_{0.8} \mathrm{Sr}_{0.2}\right)\left(\mathrm{Ga}_{1-y} \mathrm{Mg}_{y}\right) \mathrm{O}_{2.9-0.5 y}$ for $y=0.1,0.15$ and 0.2 from 298 to $1273 \mathrm{~K}$.

anomalous thermal expansion. Since the thermal expansion curves cannot be represented adequately by one or two straight lines, a fourth degree polynomial was used for curve fitting. The polynomial was of the form

$$
\frac{\Delta l}{l}=Y=B_{0}+B_{1} T+B_{2} T^{2}+B_{3} T^{3}+B_{4} T^{4},
$$

where $T$ is the absolute temperature and $B_{0}, B_{1}, B_{2}, B_{3}$ and $B_{4}$ are constants, specific to each composition. The thermal expansion coefficient denoted by $\alpha$ is given by the slope of the curve and hence for any temperature $T$, it can be expressed as the derivative of (1)

$$
\alpha=\left|\frac{\mathrm{d} Y}{\mathrm{~d} T}\right|_{T}=B_{1}+2 B_{2} T+3 B_{3} T^{2}+4 B_{4} T^{3} .
$$

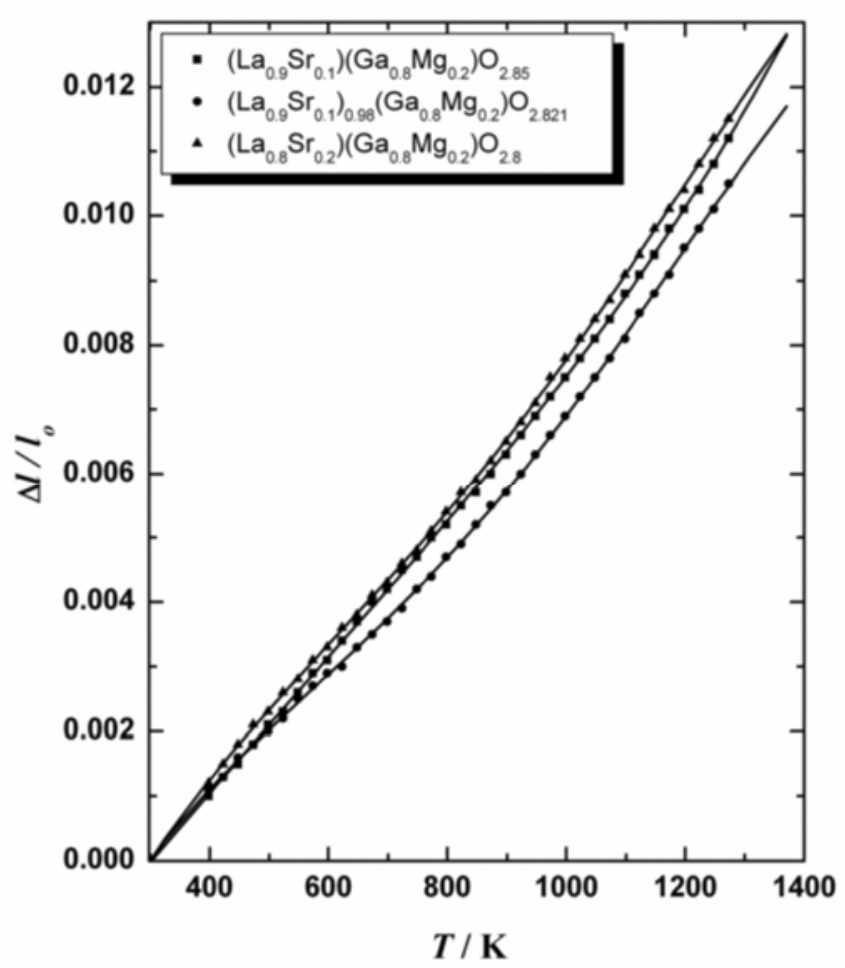

Figure 3. Thermal expansion of $\left(\mathrm{La}_{1-x} \mathrm{Sr}_{x}\right)\left(\mathrm{Ga}_{0.8} \mathrm{Mg}_{0 \cdot 2}\right) \mathrm{O}_{2 \cdot 9-0 \cdot 5 x}$ for $x=0.1$ and 0.2 and $\left(\mathrm{La}_{0.9} \mathrm{Sr}_{0.1}\right)_{0.98}\left(\mathrm{Ga}_{0.8} \mathrm{Mg}_{0.2}\right) \mathrm{O}_{2.821}$ in the temperature range from 298 to $1273 \mathrm{~K}$.

The values of $B_{0}, B_{1}, B_{2}, B_{3}$ and $B_{4}$ for various compositions are listed in table 1 . The fitted curves are shown in figure 1 . The variation of $\alpha$ with temperature is displayed in figure 2. The error in $\alpha$ is estimated to be $\pm 0 \cdot 1 \times 10^{-6} \mathrm{~K}^{-1}$. Thermal expansion coefficient for $\left(\mathrm{La}_{0.8} \mathrm{Sr}_{0.2}\right)\left(\mathrm{Ga}_{1-y} \mathrm{Mg}_{y}\right)$ $\mathrm{O}_{2.9-0.5 y}$ for $y=0 \cdot 1,0 \cdot 15$ and 0.2 shows minima between 570 and $610 \mathrm{~K}$. The minimum shifts slightly towards higher temperature with the increase in magnesium doping.

Thermal expansion curves for $\left(\mathrm{La}_{1-x} \mathrm{Sr}_{x}\right)_{1-z}\left(\mathrm{Ga}_{0.8} \mathrm{Mg}_{0.2}\right)$ $\mathrm{O}_{2.9-0.5 x}$ are shown in figure 3 . There is an increase in the thermal expansion of $\mathrm{LaGaO}_{3}$ with increase in the strontium concentration on the La-site. When the compositions on both sites are kept constant, net cation deficiency on the $A$-site causes a small decrease in thermal expansion. The variation of thermal expansion coefficient with tem- 
perature for $\left(\mathrm{La}_{1-x} \mathrm{Sr}_{x}\right)_{1-z}\left(\mathrm{Ga}_{0.8} \mathrm{Mg}_{0.2}\right) \mathrm{O}_{2.9-0.5 x}$ is shown in figure 4. TEC for $\left(\mathrm{La}_{1-x} \mathrm{Sr}_{x}\right)_{1-z}\left(\mathrm{Ga}_{0.8} \mathrm{Mg}_{0.2}\right) \mathrm{O}_{2 \cdot 9-0.5 x}$ shows a minimum between 575 and $600 \mathrm{~K}$. The minimum shifts towards lower temperature with the introduction of cation deficiency on the $A$-site.

The average thermal expansion coefficient $\left(\alpha_{\mathrm{av}}\right)$ (calculated by considering the total thermal expansion over the temperature range and deducing the change in thermal expansion per unit change in temperature) between 298 and $1273 \mathrm{~K}$ is displayed in figure 5 as a function of magnesium concentration, with constant composition at the $A$-site. Since thermal expansion is nonlinear, the average value $\left(\alpha_{\mathrm{av}}\right)$ depends on the temperature range. The variation of $\alpha_{\mathrm{av}}$ for the series $\left(\mathrm{La}_{0.8} \mathrm{Sr}_{0 \cdot 2}\right)\left(\mathrm{Ga}_{1-y} \mathrm{Mg}_{y}\right) \mathrm{O}_{2 \cdot 9-0.5 y}$ can be represented by the relation

$$
\alpha_{\text {av }}(298-1273 \mathrm{~K})=(9.95+9.4 y) \times 10^{-6} \text {. }
$$

Similarly for the series, $\left(\mathrm{La}_{1-x} \mathrm{Sr}_{x}\right)_{1-z}\left(\mathrm{Ga}_{0.8} \mathrm{Mg}_{0.2}\right) \mathrm{O}_{2 \cdot 9-0.5 x}$, the variation of the average thermal expansion coefficient with strontium concentration can be represented by

$$
\alpha_{\text {av }}(298-1273 \mathrm{~K})=(11.06+3.8 x) \times 10^{-6} \text {. }
$$

This is graphically represented in figure 6 . These linear relations are useful for estimating the average thermal expansion coefficient for compositions that have not been

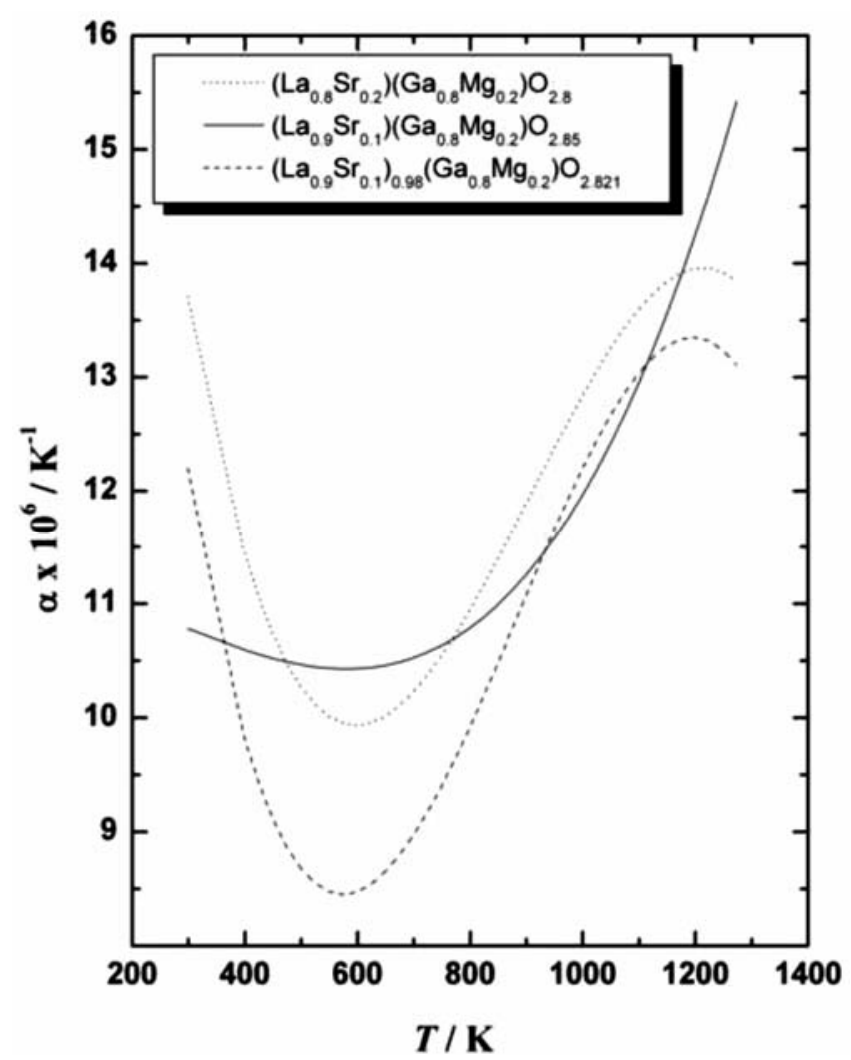

Figure 4. Variation of thermal expansion coefficient of $\left(\mathrm{La}_{1-x}\right.$ $\left.\mathrm{Sr}_{x}\right)\left(\mathrm{Ga}_{0.8} \mathrm{Mg}_{0.2}\right) \mathrm{O}_{2 \cdot 9-0.5 x}$ for $x=0.1$ and 0.2 and $\left(\mathrm{La}_{0.9} \mathrm{Sr}_{0.1}\right)_{0.98}$ $\left(\mathrm{Ga}_{0.8} \mathrm{Mg}_{0.2}\right) \mathrm{O}_{2.821}$ in the temperature range from 298 to $1273 \mathrm{~K}$. studied experimentally: $\alpha_{\mathrm{av}} \quad(298-1273 \mathrm{~K})=(11.06+$ $3 \cdot 8 x+9 \cdot 4 y) \times 10^{-6}$. It is apparent that $\mathrm{Mg}$ substitution on the Ga-site has greater effect in increasing $\alpha_{\mathrm{av}}$ than $\mathrm{Sr}$ doping on the La-site. This is contrary to Hayashi et al (2000) who suggested that thermal expansion coefficient at $200 \mathrm{~K}$ is linearly proportional to the concentration of oxygen vacancies formed as a result of doping regardless of the nature and site of the dopants. The results obtained in this study show that the thermal expansion coefficient varies linearly with oxygen vacancy concentration only when composition on one site is held constant. Reduction in the unit cell volume should result in an increase in the coefficient of thermal expansion as per Grüneisen's relation (Eastabrook 1957). Since this does not happen, it is likely that the increase in the unit cell volume is off-set by the vacancy effect. The ionic size difference between $\mathrm{La}^{3+}$ and $\mathrm{Sr}^{2+}$ as well as between $\mathrm{Ga}^{3+}$ and $\mathrm{Mg}^{2+}$ could possibly provide an explanation for the varying effects of strontium and magnesium doping on $\alpha_{\mathrm{av}}$.

The average thermal expansion coefficient also depends on the temperature range in which the SOFC electrolyte is operated. A comparison of the $\alpha_{\mathrm{av}}$ obtained in this study with the data available in the literature for few compositions of doped lanthanum gallates in different temperature ranges, is provided in figure 7 . The small difference between the results from various studies may be in part the result from microstructural effects.

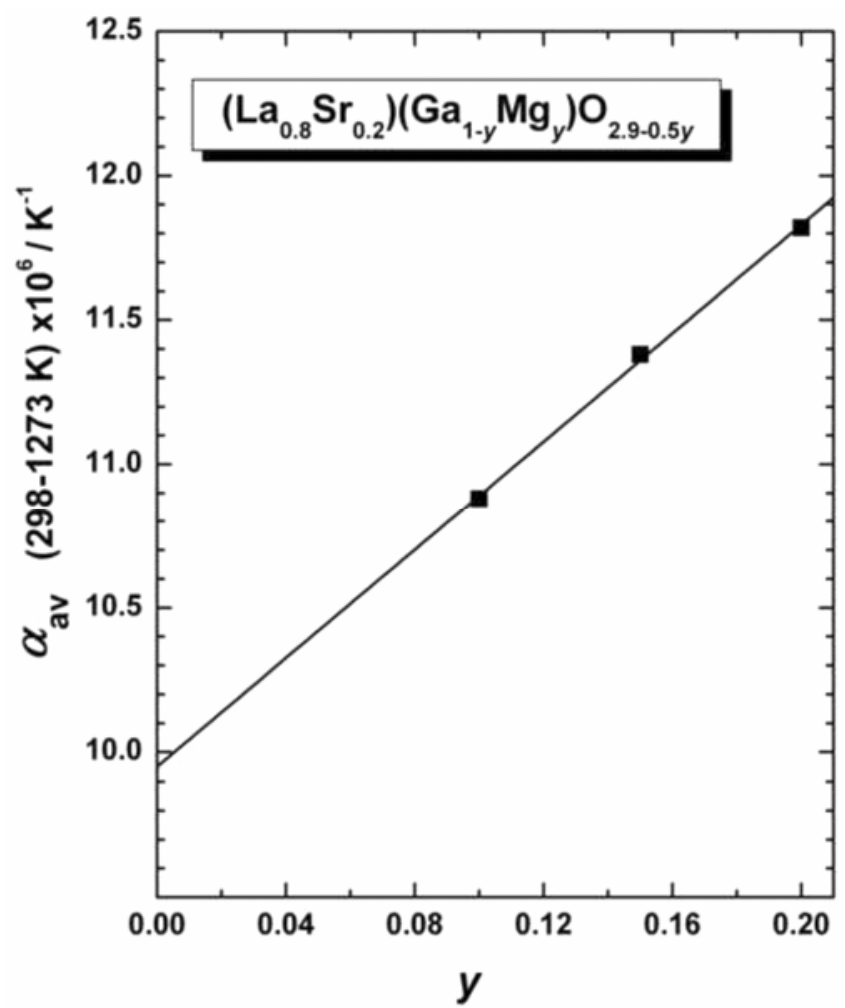

Figure 5. Average thermal expansion coefficient as a function of $\mathrm{Mg}$ concentration for the series $\left(\mathrm{La}_{0.8} \mathrm{Sr}_{0.2}\right)\left(\mathrm{Ga}_{1-y} \mathrm{Mg}_{y}\right) \mathrm{O}_{2 \cdot 9-0.5 y}$ in the temperature range from 298 to $1273 \mathrm{~K}$. 


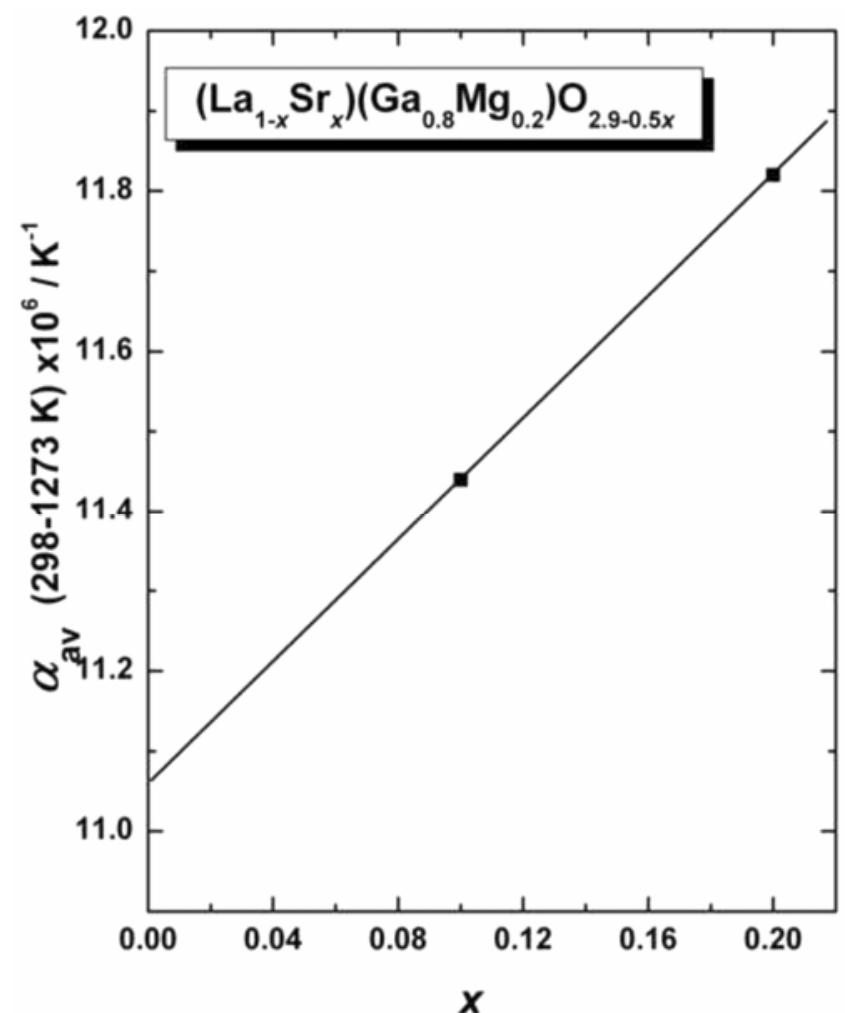

Figure 6. Average thermal expansion coefficient as a function of Sr concentration for the series $\left(\mathrm{La}_{1-x} \mathrm{Sr}_{x}\right)\left(\mathrm{Ga}_{0.8} \mathrm{Mg}_{0.2}\right) \mathrm{O}_{2 \cdot 9-0.5 x}$ in the temperature range from 298 to $1273 \mathrm{~K}$

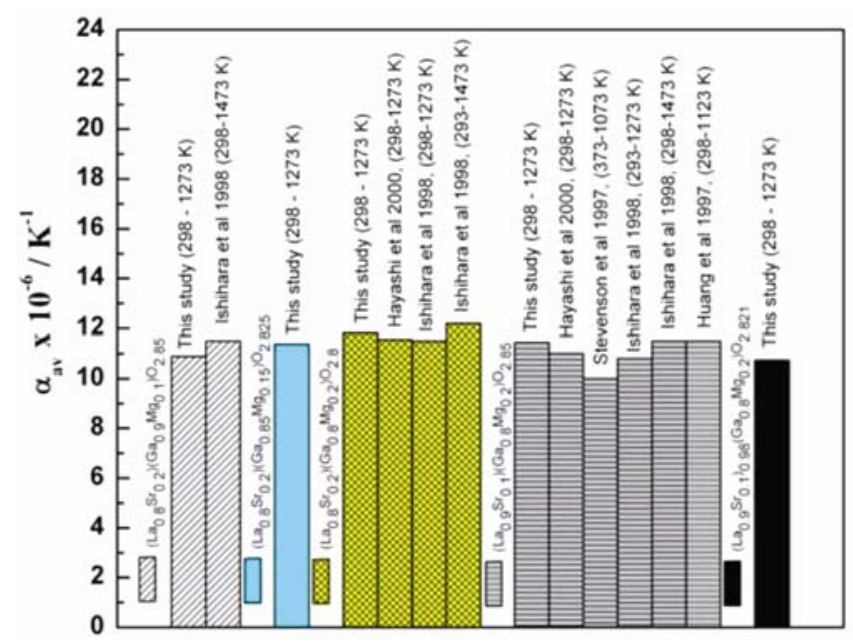

Figure 7. Comparison of the average thermal expansion coefficient obtained in the study with data available in the literature for LSGM electrolytes.

\section{Conclusions}

Thermal expansion behaviour of LSGM, including an $A$ site cation deficient composition $\left(\mathrm{La}_{0.9} \mathrm{Sr}_{0.1}\right)_{0.98}\left(\mathrm{Ga}_{0.8} \mathrm{Mg}_{0.2}\right)$ $\mathrm{O}_{2.821}$ was investigated in the temperature range from 298 to $1273 \mathrm{~K}$. Thermal expansion varied nonlinearly with temperature and became larger with the increase of dopant concentration. The $A$-site cation deficient $\left(\mathrm{La}_{0.9} \mathrm{Sr}_{0.1}\right)_{0.98}\left(\mathrm{Ga}_{0.8} \mathrm{Mg}_{0.2}\right) \mathrm{O}_{2.821}$ showed a decrease in the thermal expansion in the temperature range from 298 to $1273 \mathrm{~K}$ when compared with $\left(\mathrm{La}_{0.9} \mathrm{Sr}_{0.1}\right)\left(\mathrm{Ga}_{0.8} \mathrm{Mg}_{0.2}\right) \mathrm{O}_{2.85}$ and $\left(\mathrm{La}_{0.8} \mathrm{Sr}_{0.2}\right)\left(\mathrm{Ga}_{0.8} \mathrm{Mg}_{0.2}\right) \mathrm{O}_{2.8}$. The study clarified the dependence of TEC on oxygen vacancy concentration and revealed that the TEC varies linearly with oxygen vacancy concentration only when composition on one site of the perovskite is kept constant. Based on this result, empirical relation is proposed to predict the $\alpha_{\mathrm{av}}$ of unknown LSGM composition.

\section{Acknowledgements}

One of the authors (KTJ) acknowledges the Indian National Academy of Engineering, New Delhi, for the INAE Distinguished Professorship. (SJ) and (PVKS) thank the Indian Academy of Sciences, Bangalore, for summer research fellowships at the Indian Institute of Science as part of the academy initiative in university education.

\section{References}

Aleksandrovskii V V, Venskovskii G M, Kaleva E D, Politova S G, Prutchenko L A, Rudnitskii S, Stefanovich $\mathrm{Yu}$ and Khortova A Yu 2001 Inorg. Mater. 37758

Eastabrook E N 1957 Philos. Mag. (Eight Ser.) 21421

Feng M and Goodenough J B 1994 Eur. J. Solid State Inorg. Chem. 31663

Hayashi H, Inaba H, Matsuyama M, Lan N G, Dokiya M and Tagawa H 1999 Solid State Ionics 1221

Hayashi H, Suzuki M and Inaba H 2000 Solid State Ionics 128131

Huang K, Feng M and Goodenough J B 1997 J. Electrochem. Soc. 1443620

Ishihara T, Matsuda H and Takita Y 1995 Solid State Ionics 79147

Ishihara T, Honda M, Shibayama T, Minami H, Nishiguchi $\mathrm{H}$ and Takita Y 1998 J. Electrochem. Soc. 1453177

Marti W, Fischer P, Altorfer F, Scheel H J and Tadin J 1994 Phys. Condens. Matter 6127

Sandstrom R L et al 1988 Appl. Phys. Lett. 531874

Stevenson J W, Armstrong T R, McCready D E, Pederson L R and Weber W J 1997 J. Electrochem. Soc. 1443613 